\title{
The Evaluation Method and Empirical Study on Capability of Customer Collaborative Product Innovation
}

\author{
Xue Zhang \\ School of Management, Harbin University of Commerce, Harbin, China, 150028 \\ zxl770205@163.com
}

Keywords: Customer collaborative product innovation; Matter element model; Extension evaluation; Evaluation method; Capability of customer collaborative product innovation

\begin{abstract}
Customer collaborative product innovation is the major style of the innovation activities of enterprises, which not only needs supporting by the hardware and software environment, but the participations of both customers and staffs of enterprises. This paper analyzes the components of customer collaborative product innovation capability and establishes the matter element model for capability evaluation. Through case study, the evaluation model is illustrated qualitatively and quantitatively so as to provide important references to the decision making of customer collaborative product innovation.
\end{abstract}

\section{Introduction}

In the era of knowledge economy, innovation has become the key factor for enterprises to gain competitive advantage. Due to its own capacity and resources are limited, so the enterprise completely independent knowledge innovation will be inadequate, we must pay attention to the use of external resources. To the enterprise, all product innovation activities is to market and consumer demand for goals, the best choice for the enterprise is understanding, discovering and realizing the potential demand with customers[1-2]. At present, the research on customer collaborative product innovation (CCPI) is still in its infancy. Existing research mainly focuses on the basic theory, technology platform construction [3-4], and many problems have not yet been resolved, especially the research on the capability evaluation of customer collaborative product innovation is still lack of. Therefore, this paper makes an empirical study on this problem, in order to enrich and perfect the theory and method of CCPI.

\section{Evaluation Index of CCPI}

The Attitude and Ability of CCPI. In the temporary innovation team formed by the enterprise and the customer, if members 'innovation desire or intention is not high, then the parties would be impossible with a positive attitude to participate in the enterprise's innovation activities[5]. Therefore, collaborative innovation personnel attitude will directly affect the final results of collaborative innovation. The stronger the leadership of the enterprise, the easier it is to carry out the collaborative innovation activities smoothly. At the same time, both the customer and the enterprise should not only have enough knowledge, but also have a certain relevance, so that the knowledge of the team members can be connected with each other. In addition, knowledge absorptive capacity is also very important, it affects the knowledge for the identification, acquisition, transformation and utilization.

The Atmosphere of CCPI. How to create a dynamic atmosphere? Nonaka et al. think that the production of new knowledge must be based on the context of a situation called "Ba"[6], Knapper and Cropley believe that solving problems can generate new knowledge [7]. In a good environment, business or customer participation can trust and communicate effectively.

In CCPI, the trust between enterprises and customers can reduce the uncertainty of the innovation process, and promote the interactive learning of innovative personnel. Therefore, the two sides, especially the enterprises should try their best to create a good atmosphere. In addition, CCPI is a multi-stage process, all kinds of incentive measures should be run through the innovation 
activities.

Technical Support for CCPI. Recently, cooperative technology has been valued by the society. Y.J. Liu and X.J. Tang develop computer tools for group thinking and point out that the computer network is the base of knowledge sharing and collaborative creation [8]. The technical support of CCPI is mainly reflected in the construction level of collaborative platform and the level of software application.

Compared with the original isolated knowledge system, the integrated knowledge system involved in CCPI is more widely, such as data platform, technology platform and so on. The innovation platform provides a series of tools to help understanding the design software (such as Photoshop, 3DSMAX and other design software), however, these tools and software for individual customers are still relatively difficult to use.

Specification for CCPI. CCPI is jointly completed by the enterprise and customers, therefore, the two sides should follow the common code of conduct and norms, which is mainly reflected in the collaborative innovation process and team structure.

Barton has pointed out that the management system to guide the innovation process is one of the company's core competencies [9-10] . In order to improve the efficiency of innovation, the best way is to build a flat temporary team, which is conducive to the exchange and cooperation of members and stimulate the enthusiasm of members. $n$ addition, the rationality of the proportion of participants in the innovation team will also affect the final synergy innovation effect.

Generally speaking, the innovative ability of enterprises can quickly enhance the competitive advantage. We must use the quantitative method to carry on the science, the standard and the effective measure to the enterprise's innovation ability. Based on the existing research results, this paper combines the extension method to design the evaluation model of customer collaborative innovation capability.

\section{Evaluation Odel of Capability of CCPI}

Extension Assessment Method. Extension Method is a frequency or method that solves problem qualitatively and quantitatively. Fundamental logical cells of Extension Method included: subject, character and subject's character value, which is $\mathrm{R}=$ ( subject, character, value $)=(\mathrm{N}, \mathrm{C}, \mathrm{C}(\mathrm{N}))$. Change of three matter elements and subjects' internal structure lead to change of subject, and matter element become a basic tool to describe subject's changeability. Combined with the basic idea of extension theory, the model of customer collaborative product innovation capability evaluation is established.

Determination of Classic Field. Assume that the amount of assessment index are " $n$ ", $\mathrm{C} 1$, $\mathrm{C} 2 \ldots . . \mathrm{Cn}$; the amount of assessment level are "m", N1, N2.....Nm; then matter-element subject with the same characteristics can be demonstrated as:

$$
R=\left[\begin{array}{ccccc}
N & N_{1} & N_{2} & \cdots & N_{m} \\
C_{1} & X_{11} & X_{12} & \cdots & X_{1 m} \\
C_{2} & X_{21} & X_{22} & \cdots & X_{2 m} \\
\vdots & \vdots & \vdots & \vdots & \vdots \\
C_{n 1} & X_{n 1} & X_{n 2} & \cdots & X_{n m}
\end{array}\right]=\left[\begin{array}{ccccc}
N & N_{1} & N_{2} & \cdots & N_{m} \\
C_{1} & \left\langle a_{11}, b_{11}\right\rangle & \left\langle a_{12}, b_{12}\right\rangle & \cdots & \left.<a_{1 m}, b_{1 m}\right\rangle \\
C_{2} & \left\langle a_{21}, b_{21}\right\rangle & \left\langle a_{22}, b_{22}\right\rangle & \cdots & \left\langle a_{2 m}, b_{2 m}>\right. \\
\vdots & \vdots & \vdots & \vdots & \vdots \\
C_{n} & \left\langle a_{n 1}, b_{n 1}\right\rangle & \left\langle a_{n 2}, b_{n 2}\right\rangle & \cdots & \left\langle a_{n m}, b_{n m}>\right.
\end{array}\right]
$$

where $\left(X_{i j}\right) \mathrm{n} * \mathrm{~m}$ is matter-element matrix; $\left\langle a_{i j}, b_{i j}\right\rangle$ is the value range of index $\mathrm{Nj}$ relative to index Ci. Determinations of segment field matter elements and assessment-waiting matter elements. 
Let $R_{P}=\left(P, C, X_{P}\right)=\left[\begin{array}{ccc}P & C_{1} & X_{P 1} \\ & C_{2} & X_{P 2} \\ \vdots & \vdots \\ & C_{\mathrm{n}} & X_{P n}\end{array}\right]=\left[\begin{array}{ccc}P & C_{1} & <a_{p 1}, b_{p 1}> \\ C_{2} & <a_{p 2}, b_{p 2}> \\ \vdots & \vdots \\ C_{\mathrm{n}} & <a_{p n}, b_{p n}>\end{array}\right]$

Where $\mathrm{P}$ is the set of type; $X_{p i}$ is value rang of $\mathrm{P}$ relative to $\mathrm{C}_{\mathrm{i}}$, that is segment field $\left\langle a_{p i}, b_{p i}\right\rangle$. Indicate investigated data by matter elements, then assessment-waiting matter elements $\mathrm{P}_{0}$ can be $R_{0}=\left(P_{0}, C_{i}, x_{i}\right)=\left[\begin{array}{ccc}P_{0} & C_{1} & x_{1} \\ & C_{2} & x_{2} \\ \vdots & \vdots \\ & C_{n} & x_{n}\end{array}\right]$, Where ${ }^{x_{i}}$ is value of $\mathrm{P}_{0}$ relative to index $\mathrm{C}_{\mathrm{i}}$, that is practical data of assessment-waiting matter.

Determinations of weighted parameter and correlation function of assessment category.

a) Let $w_{i}$ represent weighted parameter of index $\mathrm{Ci}, \sum_{i=1}^{n} w_{i}=1$ 。

$b$ ) Calculate position value

$$
D\left(x_{i}, X_{i j}, X_{p i}\right)= \begin{cases}\rho\left(x_{i}, X_{p i}\right)-\rho\left(x_{i}, X_{i j}\right) & x_{i} \in X_{i j} \\ -1 & x_{i} \in X_{i j}\end{cases}
$$

Where $\rho\left(x_{i}, X_{p i}\right)$ represents distance between dot and interval ${ }_{p i}$, represents distance between dot and interval. $X_{i j}$

c) Calculation of Correlation Function

$$
K_{j}\left(x_{i}\right)=\frac{\rho\left(x_{i}, X_{i j}\right)}{D\left(x_{i}, X_{i j}, X_{p i}\right)}= \begin{cases}\frac{\rho\left(x_{i}, X_{i j}\right)}{\rho\left(x_{i}, X_{p i}\right)-\rho\left(x_{i}, X_{i j}\right)} & D\left(x_{i}, X_{i j}, X_{p i}\right) \neq 0 \\ \rho\left(x_{i}, X_{i j}\right)-1 & D\left(x_{i}, X_{i j}, X_{p i}\right)=0\end{cases}
$$

Correlation function $K_{j}\left(x_{i}\right)$ represents attribution of assessment-waiting matter's each index relative to category " $\mathrm{j}$ ”.

d) Calculate correlation degree of assessment-waiting matter relative to level “ $\mathrm{j}$ ”

$$
K_{j}\left(P_{0}\right)=\sum_{i=1}^{n} w_{i} K_{j}\left(x_{i}\right)
$$

If $K_{j 0}\left(P_{0}\right)=\max _{j \in\{1,2}\left(P_{0}\right)$, then assessment-waiting matter belongs to category $j_{0}$, Let $j \in\{1,2 \cdots m\}$

$$
j^{*}=\frac{\sum_{j=1}^{m} j \times \overline{K_{j}\left(P_{0}\right)}}{\sum_{j=1}^{m} \overline{K_{j}\left(P_{0}\right)}}
$$

Where $j^{*}$ is called level variable value of P0.

Extension Model for Capability Evaluation of CCPI. The correct selection of evaluation index is necessary for the further research on the innovation ability. However, what kind of evaluation index of innovation ability actually is still a difficult problem to be solved. Scherer, an 
American economist, thinks that it is impossible to find a universal implementation for the evaluation index or system, it can only be based on different types of innovation using different indicators.

In the survey of enterprise innovation capability, the proportion of the cost of enterprise innovation in Germany accounted for the proportion of enterprise sales.

On the basis of the existing research results and the composition of customer collaborative product innovation capability, select evaluation index $\mathrm{C} 1$ as the attitude and ability of collaborative product innovation, $\mathrm{C} 2$ as the atmosphere of Collaborative product innovation, C3 as Technical support for collaborative product innovation, C4 as Specification for collaborative product innovation. Based on Delphi Method, establish matter-element entirety with the same characteristics (Classical fields).

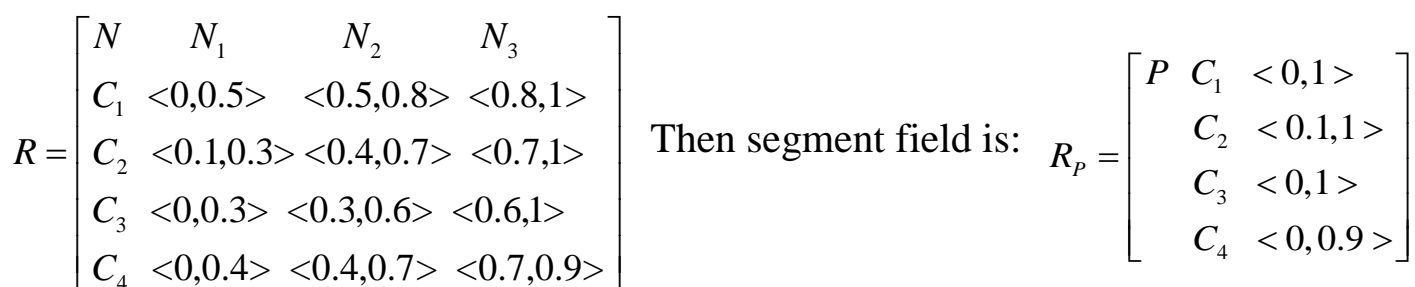

Where $\mathrm{P}$ is the entirety of levels for performance evaluation of customer collaboration innovation implementation, which in this study is categorized as three levels: low, medium and high.

This study selects five groups of customer collaboration innovation projects, and then establishes the matter element to be evaluated:

$$
R_{0}=\left[\begin{array}{cccccc}
P & P_{1} & P_{2} & P_{3} & P_{4} & P_{5} \\
C_{1} & 0.85 & 0.83 & 0.95 & 0.77 & 0.92 \\
C_{2} & 0.82 & 0.90 & 0.94 & 0.78 & 0.95 \\
C_{3} & 0.80 & 0.60 & 0.60 & 0.85 & 0.68 \\
C_{4} & 0.50 & 0.45 & 0.60 & 0.49 & 0.66
\end{array}\right]
$$

Weight coefficient plays an important role in superiority assessment. Since man-made weight coefficients are usually of subjective cognitions which affect objectivity and reliability of assessment process, this paper adopts SHAPLEY to determine the weight coefficient of risk assessment index in collaboration innovation (Table 1).

Put data and weight coefficient of R0 into formula (1,.,. (.). Figure out correlation degree of assessment-waiting project relative to each assessment level; Figure out value of level variable (j*). Assessment results are shown in table 2.

According to evaluation results in Fig. 2, the group 3 of CCPI belongs to the bad implementation performance level 1; group 2 and group 5 belong to the medium implementation performance level 2; group 1 and group 4 belong to the good implementation performance level 3. It can be seen that the capability of CCPI could be directly and quantitatively reflected by extension evaluation method, which undoubtedly facilitates the decision making of enterprises' collaboration innovation.

Table 1 Weight factor and assessment index

\begin{tabular}{|c|c|c|c|c|}
\hline assessment index & $\mathrm{C}_{1}$ & $\mathrm{C}_{2}$ & $\mathrm{C}_{3}$ & $\mathrm{C}_{4}$ \\
\hline weight factor & 0.32 & 0.28 & 0.25 & 0.15 \\
\hline
\end{tabular}


Table 2 Correlation and assessment result

\begin{tabular}{|c|c|c|c|c|c|c|}
\hline Project & $\mathrm{N}_{1 \text { (低) }}$ & $\mathrm{N}_{2 \text { (中) }}$ & $\mathrm{N}_{3 \text { (高) }}$ & $\mathrm{j}$ & $\mathrm{j}^{*}$ & $\begin{array}{c}\text { Assessment } \\
\text { result }\end{array}$ \\
\hline 1 & -0.646 & -0.43 & 0.081 & 3 & 3 & High \\
\hline 2 & -0.022 & -0.124 & -0.362 & 2 & 2.3 & medium \\
\hline 3 & 0.064 & -0.786 & -0.885 & 1 & 1.21 & low \\
\hline 4 & -0.135 & 0.093 & -0.345 & 3 & 2.51 & high \\
\hline 5 & 0.048 & -0.332 & -0.654 & 2 & 1.85 & medium \\
\hline
\end{tabular}

\section{Summary}

Matter element is an effective formal tool with wide-range of application which is capable of directly reflecting the quality and quantity of matter and vividly depicting its changing process. This study establishes multi-indices matter element model for capability of customer collaborative product innovation by applying extension method and provides quantitative evaluation results. In generic, this study deepens current research on qualitative analysis on capability of customer collaborative product innovation and illustrates a quantitative evaluation approach, which undoubtedly provides significant references for the decision making of customer collaboration innovation.

\section{Acknowledgements}

National Natural Foundation Project (71371061): Research on coordination and mutation response of customer oriented supply chain network. (China)

Philosophy and Social Sciences Planning in Heilongjiang Province (14E011): Research on the management innovation of small and medium enterprises in Heilongjiang Province Based on cloud economy. (China)

Doctoral research project of Harbin University of Commerce (12DW014): Research on the capability evaluation and improving ways of CCPI oriented to enterprise competitive advantage. (China)

\section{References}

[1] V. Ojanen and J. Hallikas: Inter-organisational routines and transformation of customer relationships in collaborative innovation. International Journal of Technology Management, Vol. 45 (2009) No.3, p. 306-322.

[2] L.G. Shen, W. Zhao and M.J. Li: A new method for customer-oriented virtual collaborative design with VRML product model. Computer Supported Cooperative Work in Design (2007). p. 197-206.

[3] T.L.Sun: Supporting customer-company interaction in product customization using a web-based collaborative VR environment. Institute of Industrial Engineers, Vol. 22 (2005) No.3, p. 35-42.

[4] Cellini R, Lambertini L. Dynamic R\&D with spill overs: competition vs. cooperation. Journal of Economic Dynamics \& Control, Vol. 33 (2009) No.1, p. 568-582.

[5] Elofson, Greg and Robinson: Collective customer collaboration impacts on supply- chain performance, International Journal of Production Research, Vol.45 (2007) No.11, p.2567-2594.

[6] I.Nonaka, R.Toyama and N.Konno: SECI, Ba and Leadership: A unified model of dynamic knowledge creation. Long Range Planning, Vol.33 (2000) No.1,p.5-34. 
[7] C.K. Knapper and A.J. Cropley: Lifelong Learning in Higher Education. (Kogan Page, London 2000) p.121-124.

[8] Y.J. Liu and X.J. Tang. Field for supporting cooperation and product innovation. Journal of Management Science, Vol.9 (2006) No.1, p. 79-85. (In Chinese)

[9] L. Barton. G. Capabilities, C.Rigidities: A paradox in managing new product development. Strategic Management Journal, Vol.13 (1992) No.1,p. 111-115.

[10]X.L. WANG, Y.YANG and Q.S.XING: Research on the influencing factors of customer collaborative product innovation performance based on FCA method. Science \& Technology Progress and Policy, Vol. 27 (2010) No.18, p. 77-82. (In Chinese) 